\title{
A cross-population study of sexual dimorphism in the bony labyrinth
}

\author{
Alexandra Uhl ${ }^{1}$ - Fotios Alexandros Karakostis ${ }^{1}$. Joachim Wahl ${ }^{2,3} \cdot$ Katerina Harvati ${ }^{1,4}$
}

Received: 18 May 2019 / Accepted: 12 March 2020 / Published online: 10 June 2020

(C) The Author(s) 2020

\begin{abstract}
Previous research found sexual dimorphism in the bony labyrinth of a Greek population sample (Osipov et al. 2013). This study intends to investigate the nature of this structure's sexual dimorphism across populations of diverse geographic origin and to identify the effect of inter-population variation on the accuracy of determining sex using the bony labyrinth. Three population samples of known sex were analyzed originating from Europe $(n=30)$, Africa $(n=38)$, and North America $(n=30)$. The discriminant function developed in Osipov et al. (2013) was applied, and new function equations for sex estimation were developed. In addition, we used principal component analyses for investigating population differences, while bivariate tests were used to compare across population samples, sexes, and anatomical sides. A significant level of sexual dimorphism was found in all population samples, being driven by both size and shape differences. Discriminant functions for sex estimation were developed for all three population samples combined (71.4\% accuracy) as well as separately (70-80\% accuracy). The German sample was the least sexually dimorphic, whereas the North American sample exhibited the greatest sexual dimorphism. The size and shape of the bony labyrinth also significantly differed across population samples. The bony labyrinth is found to be sexually dimorphic across distinct population groups. Due to significant differences across our population samples, the accuracy of the previously proposed method for sex determination (Osipov et al., 2013) was relatively low. For this purpose, this study presented new functions, whose accuracy was tested in three distinct population samples.
\end{abstract}

Keywords Sexual dimorphism $\cdot$ Inner ear $\cdot$ Bony labyrinth

\section{Introduction}

Electronic supplementary material The online version of this article (https://doi.org/10.1007/s12520-020-01046-w) contains supplementary material, which is available to authorized users.

Alexandra Uhl

alexuh116@gmail.com

1 Paleoanthropology, Senckenberg Centre of Human Evolution and Palaeoenvironments, Eberhard Karls University of Tübingen, Tübingen D-72070, Germany

2 Paleoanthropology, Eberhard Karls University of Tübingen, D-72070 Tübingen, Germany

3 Landesamt für Denkmalpflege im Regierungspräsidium Stuttgart, D-78467 Konstanz, Germany

4 DFG Centre of Advanced Studies 'Words, Bones, Genes, Tools', Eberhard Karls University of Tübingen, D-72070 Tübingen, Germany
The bony labyrinth, the osseous cavity inside the petrous bone and surrounding the inner ear, accommodates the organs for balance and hearing. While it has been studied extensively for locomotor and phylogenetic differences across extant and fossil species (i.e., Spoor et al. 1994; Hublin et al. 1996; Spoor and Zonneveld 1998; Spoor 2003; Spoor 2003; Bouchneb and Crevecoeur 2009; Cox and Jeffery 2010; Gunz et al. 2012; Braga et al. 2013; El Khoury et al. 2014; Hill et al. 2014), there is limited research looking at the sexual dimorphism of bony labyrinth in Homo sapiens. Earlier efforts detected sexual dimorphism in the superficial structure of the Facies posterior and the angle of the internal acoustic meatus (i.e., Wahl and Henke 1980; Graw and Wahl 1999; Graw and Wahl 2000; Wahl and Graw 2001; Graw et al. 2005) indicating that the bony labyrinth is encased and surrounded by sexually dimorphic boney features.

Several other studies have reported sexual dimorphism of the bony labyrinth. The cochlea has been found by several 
authors to be sexually dimorphic with males having longer cochlea (Hardy 1938; Sato et al. 1991; Miller 2007). Spoor (1993) reported no significant sexual dimorphism in the labyrinth, but that study used a sample of mixed geographic origin and no known sex. More recently, Osipov et al. (2013) reported significant sexual dimorphism in a Cretan (Greek) population and $82.4 \%$ discriminant accuracy was achieved using a discriminant function, while El Khoury et al. (2014) reported sexual dimorphism of the semi-circular canal angles in a French sample.

Osipov et al. (2013) found that the most sexually dimorphic variable was the curvature of the posterior semi-circular canal (Osipov et al. 2013). Spoor (1993) estimated that sexual dimorphism of the bony labyrinth was caused by body size rather than actual sex differences. Osipov et al. (2013) not only reported sexually dimorphic shape differences of the lateral canal in the Cretan sample studied but also reported that sexual dimorphism was caused mostly by size. In this study, we aim to assess whether the sexually dimorphic morphology reported by Osipov et al. (2013) and others can be found in populations of diverse geographical origin, and particularly in non-European populations. As with many sexually dimorphic skeletal features, and as Osipov et al. (2013) pointed out, we hypothesized that the bony labyrinth will also exhibit population-specific sexual dimorphism. We applied the discriminant functions developed in Osipov et al. (2013) to test their applicability across diverse groups. Furthermore, we developed new functions based on a dataset involving individuals from distinct population groups.

\section{Materials and methods}

The samples used in this study consist of crania from 98 modern human adults of known sex from three geographic populations. Table 1 lists all specimens used. Sex information for the Zulu and German individuals is known based on collection records consisting of demographic historical documentation. Sex for the Oneota sample was estimated based either on ancient DNA analyses or on the morphology of the bony pelvis (Milner and Smith 1990; Stone et al. 1996; Stone and Stoneking 1998).

Table 1 Sample demographics
The virtual reconstruction of the crania was performed on site. Particularly, the Zulu sample was scanned at the Palaeosciences Centre Microfocus X-ray Computed Tomography (CT) Facility, University of the Witwatersrand with a Nikon Metrology XTH $225 / 320 \mathrm{LC}$ at $100 \mathrm{kV}, 105 \mu \mathrm{A}$, with an exposure of $500 \mathrm{~ms}$ per image, resolution between 60 and $120 \mu \mathrm{m}$ and a 1.8AI filter. The sample from Germany was scanned at the Paleoanthropology High Resolution CT Laboratory, Eberhard Karls University Tübingen, using a Phoenix v|tome|x microCT scanner (General Electric) and $180 \mathrm{kV}, 120 \mu \mathrm{A}, 2500$ images per scan with an exposure of 200 milliseconds (ms) per image and a resolution between 101 and $116 \mu \mathrm{m}$ with a $0.1 \mathrm{Cu}$ filter. Slices had a pixel size between $0.101 \times 0.101 \mathrm{~mm}$ and $0.116 \times 0.116 \mathrm{~mm}$. The Norris Farms Oneota specimens were scanned with X-ray source energy settings at $150-180 \mathrm{kV}$ and between 120 and $200 \mathrm{lA}$, with 2400 views and two-three samples per view. Slice thicknesses ranged from 0.0615 to $0.0781 \mathrm{~mm}$, depending on the size of the specimen. The field of view ranged from 63 to $82 \mathrm{~mm}$, producing pixel sizes ranging from 0.0615 to $0.0781 \mathrm{~mm}$.

When available, both the left and right bony labyrinths were segmented using Avizo software (FEI Company, Hillsboro, OR, USA). Measurements of the three semicircular canals and cochlea were made following Osipov et al. (2013) by one of us (AU) on generated 3D virtual endocasts of this structure.

Measurements included the height and width of each of the semi-circular canals and the cochlea in millimeters $(\mathrm{mm})$ (see Table 2). Osipov et al. (2013) used mathematical indices for relative size and shape, following Spoor and Zonneveld (1995), which we also use. These include the radius of curvature (R), calculated as 0.5 (height + width) $/ 2$ and indices of height to width $(\mathrm{h} / \mathrm{w})$. The radius of curvature provides overall size information and the height/width index provides shape information. Following Spoor (2003), the sagittal labyrinthine index (SLI) was also used. SLI represents the position of the lateral canal relative to the posterior canal and is calculated as $\mathrm{SLIi} /(\mathrm{SLIs}+\mathrm{SLIi}) \times 100$ using dimensions SLI inferior (from the plane of the lateral canal to the lower point of the posterior canal arc) and SLI superior (from the plane of the lateral canal to the higher point of the posterior canal arc; Spoor 2003). Following previous work (i.e., Bouchneb and Crevecoeur

\begin{tabular}{llllll}
\hline Population & Males & Females & Total & Location & Date \\
\hline Norris Farms Oneota $^{\mathrm{a}}$ & 16 & 14 & 30 & Illinois, U.S.A. & A.D. 1300 \\
Zulu & 17 & 21 & 38 & South Africa & Early twentieth century \\
German & 17 & 13 & 30 & Baden-Württemberg & Nineteenth century \\
Total & 50 & 48 & 98 & & \\
\hline
\end{tabular}

${ }^{\text {a }}$ For the Norris Farms Oneota Sample, the left and right bony labyrinths were available for 18 out of 30 individuals. Analyses use mean values from the right and left variables, except for 12 Oneota individuals for which only the right side was available 
2009; Osipov et al. 2013; Uhl et al. 2016), the mean of the left and right sides was used for analyses.

The Oneota sample had fewer left temporal bones $(n=18)$ available for study than right temporal bones $(n=30)$, thus, for 12 of the Oneota, we cannot use the mean and instead use the right-side measurements. A paired $t$ test was conducted to assess any issues with asymmetry between the left and right sides.

In order to assess intra-observer error, a total of five individuals were measured three times each. The percent error (percent of variation across the three measurements) for all obtained measurements of the semi-circular canals and cochlea was below $5 \%$ in all cases, ranging from $0.76 \%$ to $3.35 \%$ (Online resource 3 ). This error range is comparable to the one reported by Osipov et al. (2013).

We applied the discriminant function of the highest accuracy (Function 1) developed by Osipov et al. (2013) on their Cretan sample, which had $82.4 \%$ accuracy in that study, to the populations studied here. Function 1 is:

$$
\begin{gathered}
(\mathrm{PSChM} \times 0.728)+(\mathrm{PSCwM} \times 1.407) \\
+(\mathrm{LSChwM} \times 6.217)+(-18.749)
\end{gathered}
$$

An individual is assigned the sex of male if the resulting value is $>0$ and female if it is $<0$. After applying function 1 to all the individuals, we used Cohen's kappa statistic (Cohen

Table 2 List of measurements and abbreviations. All measurements are in $\mathrm{mm}$

\begin{tabular}{ll}
\hline Abbreviation & Bony labyrinth dimension \\
\hline ASCh & Anterior canal height \\
ASCw & Anterior canal width \\
ASCdh & Anterior canal diagonal height \\
ASCdw & Anterior canal diagonal width \\
PSCh & Posterior canal height \\
PSCw & Posterior canal width \\
LSCh & Lateral canal height \\
LSCw & Lateral canal width \\
Coh & Cochlear basal turn height \\
Cow & Cochlear basal turn width \\
ASChw & Anterior canal shape index-height/width \\
ASCdhw & Anterior canal diagonal shape index-height/width \\
PSChw & Posterior canal shape index-height/width \\
LSChw & Lateral canal shape index-height/width \\
Cohw & Cochlear basal turn shape index-height/width \\
ASCR & Anterior canal radius of curvature \\
ASCdR & Anterior canal diagonal radius of curvature \\
PSCR & Posterior canal radius of curvature \\
LSCR & Lateral canal radius of curvature \\
COR & Cochlear basal turn radius of curvature \\
\hline
\end{tabular}

1960) to further assess the level of agreement between the actual sex and estimated sex. According to Altman (1991), the strength of agreement for a value of $\mathrm{K}$ is as follows: < 0.20: poor; $0.21-0.40$ : fair; $0.41-0.60$ : moderate; $0.61-0.80$ : good; and $0.81-1.00$ : very good.

Additionally, using step-wise discriminant analysis, we created new cross-validated discriminant functions based on the samples studied here, which can be used to estimate the sex of an unknown individual. All assumptions of discriminant function analysis were met (Tabachnick and Fidell 2001; Field 2013). As the $P$ value of the Box's M was high (over 0.05), a within-groups covariance matrix was used (Field 2013). Subsequently, the unstandardized function coefficients, the constant, the group centroids, and the sectioning points between males and females were calculated (Tabachnick and Fidell 2001; Field 2013).

The accuracy of each function was computed based on the discriminant scores of specimens both before and after crossvalidation (following a "leave one out classification" procedure) (Field 2013). Furthermore, for each of the newly created discriminant functions, kappa statistics were applied (as described above) to assess the level of agreement between estimated and actual sex. To apply each newly created function to an individual of unknown sex, the corresponding measurement is multiplied by the function coefficient for that variable. The resulting values are added to the function's constant (Field 2013).

Following Osipov et al. (2013), bilateral asymmetry of each population was assessed using paired $t$ tests. Osipov et al. (2013) found significant asymmetry for several bony labyrinth dimensions. Thus, we also expected some level of asymmetry in our samples. The Osipov et al. (2013) functions for sex estimation were created based on a Cretan sample. In order to create population-specific discriminant functions for the populations studied here, a cross-validated step-wise discriminant analysis was carried out using all three populations together $(n=98)$ and then each sample separately. Then, the accuracy for sex estimation of the resulting functions was compared to the previously created Osipov et al. (2013) function.

We conducted a principal component analysis (PCA) to assess the affinities of the three populations studied and the

Table 3 Accuracy of sex estimation function 1 from Osipov et al. (2013) and kappa statistics as applied to the German, Zulu, and Oneota populations separately and in the final row, all samples together

\begin{tabular}{lllll} 
Population & Sample size & Accuracy $(\%)$ & Kappa value & Significance \\
\hline German & 30 & 66.67 & 0.321 & 0.078 \\
Zulu & 38 & 68.42 & 0.323 & 0.016 \\
Oneota & 30 & 73.33 & 0.478 & 0.004 \\
Total & 98 & 69.39 & 0.321 & 0.078 \\
\hline
\end{tabular}


Table 4 Multivariate discriminant function for sex estimation, cross-validated classification accuracies, and kappa statistics. Abbreviations as in Table 2

\begin{tabular}{|c|c|c|c|c|}
\hline $\begin{array}{l}\text { Population } \\
\text { Variable }\end{array}$ & $\begin{array}{l}\text { German } \\
\text { PSCMR }\end{array}$ & $\begin{array}{l}\text { Zulu } \\
\text { ASCMR }\end{array}$ & $\begin{array}{l}\text { Oneota } \\
\text { CMR }\end{array}$ & $\begin{array}{l}\text { All samples } \\
\text { PSCMR }\end{array}$ \\
\hline Function coefficient & 4.262 & 4.469 & 10.488 & 3.840 \\
\hline constant & -13.662 & -13.570 & -24.143 & -11.548 \\
\hline Male centroid & 0.388 & 0.574 & 0.693 & 0.433 \\
\hline Female centroid & -0.508 & -0.465 & -0.793 & -0.451 \\
\hline Male/female demarking point & -0.120 & 0.109 & -0.100 & -0.018 \\
\hline Cross validated accuracy (\%) & 70.0 & 71.1 & 80 & 71.4 \\
\hline Kappa statistic & 0.405 & 0.518 & 0.598 & 0.429 \\
\hline Kappa significance & 0.024 & 0.001 & 0.001 & 0.000 \\
\hline
\end{tabular}

males and females of each population. Given that the variables presented different scales (Table 1), a correlation matrix was used. The number of principal components plotted was decided based on the scree-plot technique (Field 2013). In order to remove the effects of size from our analyses, a second round of discriminant analyses and a second PCA were carried out

Table 5 Independent $t$ test results for sexual dimorphism within all samples (German, Zulu, Norris Farms Oneota). Mean values, standard deviation, and $P$ values. Mean values for height and width measurements are in $\mathrm{mm}, \mathrm{h} / \mathrm{w}, \mathrm{SLI}$ and $\mathrm{R}$ are indices. Significant $P$ values are in bold type. Abbreviations as in Table 2

\begin{tabular}{|c|c|c|c|c|c|}
\hline \multirow[b]{3}{*}{ Variable } & \multicolumn{4}{|c|}{ All populations } & \multirow[b]{3}{*}{$P$ value } \\
\hline & \multicolumn{2}{|c|}{ Males $(n=50)$} & \multicolumn{2}{|c|}{ Females $(n=48)$} & \\
\hline & Mean & $\mathrm{SD}$ & Mean & $\mathrm{SD}$ & \\
\hline SLIM & 49.45 & 5.49 & 48.45 & 5.33 & 0.362 \\
\hline ASChM & 6.91 & 0.54 & 5.67 & 0.51 & 0.000 \\
\hline ASCwM & 6.91 & 0.54 & 6.52 & 0.47 & 0.000 \\
\hline ASChwM & 0.88 & 0.04 & 0.87 & 0.05 & 0.200 \\
\hline ASCMR & 3.25 & 0.26 & 3.05 & 0.23 & 0.000 \\
\hline ASCdhM & 6.65 & 0.60 & 6.19 & 0.54 & 0.000 \\
\hline ASCdwM & 6.47 & 0.54 & 6.05 & 0.48 & 0.000 \\
\hline ASCdhwM & 1.03 & 0.06 & 1.02 & 0.05 & 0.699 \\
\hline ASCdMR & 3.28 & 0.27 & 3.06 & 0.24 & 0.000 \\
\hline LSChM & 4.56 & 0.53 & 4.25 & 0.53 & 0.004 \\
\hline LSCwM & 5.01 & 0.54 & 4.73 & 0.54 & 0.004 \\
\hline LSChwM & 0.91 & 0.07 & 0.90 & 0.07 & 0.402 \\
\hline LSCMR & 2.39 & 0.22 & 2.24 & 0.25 & 0.002 \\
\hline PSChM & 6.38 & 0.71 & 5.83 & 0.61 & 0.000 \\
\hline PSCwM & 6.10 & 0.48 & 5.73 & 0.43 & 0.000 \\
\hline PSChwM & 1.05 & 0.08 & 1.02 & 0.07 & 0.064 \\
\hline PSCMR & 3.12 & 0.28 & 2.89 & 0.24 & 0.000 \\
\hline $\mathrm{ChM}$ & 5.11 & 0.32 & 4.96 & 0.35 & 0.021 \\
\hline $\mathrm{CwM}$ & 4.01 & 0.41 & 3.88 & 0.28 & 0.089 \\
\hline ChwM & 1.30 & 0.13 & 1.28 & 0.11 & 0.764 \\
\hline CMR & 2.28 & 0.14 & 2.21 & 0.12 & 0.011 \\
\hline
\end{tabular}

with size-adjusted data. For this process, only the variables that are purely size-based were used (those for height and width of the canals and cochlea) and not those variables already reflecting shape (ratios) or overall shape/size (the radii variables). Using these ten variables, we follow methods outlined in the literature for size-adjusting metric variables

Table 6 Independent $t$ test results for sexual dimorphism in the German sample. Mean values, standard deviation, and $P$ values. Mean values for height and width measurements are in $\mathrm{mm}, \mathrm{h} / \mathrm{w}, \mathrm{SLI}$ and $\mathrm{R}$ are indices. Significant $P$ values are in bold type. Abbreviations as in Table 2

German sample

\begin{tabular}{|c|c|c|c|c|c|}
\hline \multirow[b]{2}{*}{ Variable } & \multicolumn{2}{|c|}{ Males $(n=17)$} & \multicolumn{2}{|c|}{ Females $(n=13)$} & \multirow[b]{2}{*}{$P$ value } \\
\hline & Mean & SD & Mean & SD & \\
\hline SLIM & 49.04 & 4.55 & 48.16 & 5.12 & 0.621 \\
\hline ASChM & 6.35 & 0.56 & 6.08 & 0.49 & 0.186 \\
\hline ASCwM & 7.00 & 0.57 & 6.80 & 0.44 & 0.320 \\
\hline ASChwM & 0.91 & 0.04 & 0.89 & 0.05 & 0.427 \\
\hline ASCMR & 3.34 & 0.27 & 3.22 & 0.22 & 0.218 \\
\hline ASCdhM & 6.97 & 0.63 & 6.70 & 0.40 & 0.187 \\
\hline ASCdwM & 6.62 & 0.53 & 6.34 & 0.47 & 0.138 \\
\hline ASCdhwM & 1.05 & 0.06 & 1.06 & 0.05 & 0.749 \\
\hline ASCdMR & 3.40 & 0.28 & 3.26 & 0.21 & 0.137 \\
\hline LSChM & 4.86 & 0.59 & 4.58 & 0.46 & 0.162 \\
\hline LSCwM & 5.12 & 0.48 & 4.94 & 0.47 & 0.355 \\
\hline LSChwM & 0.95 & 0.06 & 0.93 & 0.06 & 0.280 \\
\hline LSCMR & 2.50 & 0.26 & 2.38 & 0.22 & 0.218 \\
\hline PSChM & 6.95 & 0.59 & 6.41 & 0.58 & 0.020 \\
\hline PSCwM & 6.24 & 0.41 & 5.93 & 0.43 & 0.052 \\
\hline PSChwM & 1.11 & 0.07 & 1.08 & 0.06 & 0.206 \\
\hline PSCMR & 3.30 & 0.23 & 3.09 & 0.24 & 0.022 \\
\hline $\mathrm{ChM}$ & 5.32 & 0.31 & 5.24 & 0.30 & 0.494 \\
\hline CwM & 3.88 & 0.34 & 3.74 & 0.20 & 0.204 \\
\hline ChwM & 1.37 & 0.11 & 1.40 & 0.06 & 0.498 \\
\hline CMR & 2.30 & 0.13 & 2.25 & 0.11 & 0.255 \\
\hline
\end{tabular}


(i.e., Lague et al. 2008). We calculated the geometric mean for each individual (based on all ten height and width variables) and then divided each individual's value by its own geometric mean. This standardization removes isometric size information (Falsetti et al. 1993).

In order to assess if the means of the populations differ significantly from one another, an ANOVA and Tukey Posthoc test were used. All statistical analyses were carried out using the SPSS 21 software package (Armonk, NY: IBM Corp) and the PAST software, version $2.17 \mathrm{c}$ (Hammer et al. 2001).

\section{Results}

All variables were found to be normally distributed based on a Shapiro-Wilk test ( $P$ values over 0.05 ). There were no outliers in any of the variables, while a Q-Q plot showed normal distribution. Moreover, as previously mentioned, Box's M test was not significant, indicating that variance is homogeneous (Field 2013).

Table 7 Independent $t$ test results for sexual dimorphism in the Zulu sample. Mean values, standard deviation, and $P$ values. Mean values for height and width measurements are in $\mathrm{mm}, \mathrm{h} / \mathrm{w}, \mathrm{SLI}$ and $\mathrm{R}$ are indices. Significant $P$ values are in bold type. Abbreviations as in Table 2

Zulu sample

\begin{tabular}{|c|c|c|c|c|c|}
\hline \multirow{2}{*}{$\begin{array}{l}1 \\
\text { Variable }\end{array}$} & \multicolumn{2}{|c|}{ Males $(n=17)$} & \multicolumn{2}{|c|}{ Females $(n=21)$} & \multirow{2}{*}{$\begin{array}{l}2 \\
P \text { value }\end{array}$} \\
\hline & Mean & SD & Mean & $\mathrm{SD}$ & \\
\hline SLIM & 53.05 & 5.24 & 49.40 & 6.09 & 0.059 \\
\hline ASChM & 5.94 & 0.57 & 5.46 & 0.34 & 0.003 \\
\hline ASCwM & 6.72 & 0.55 & 6.27 & 0.38 & 0.005 \\
\hline ASChwM & 0.88 & 0.03 & 0.87 & 0.04 & 0.419 \\
\hline ASCMR & 3.16 & 0.28 & 2.93 & 0.17 & 0.003 \\
\hline ASCdhM & 6.46 & 0.56 & 5.94 & 0.40 & 0.002 \\
\hline ASCdwM & 6.19 & 0.58 & 5.80 & 0.38 & 0.017 \\
\hline ASCdhwM & 1.04 & 0.04 & 1.03 & 0.04 & 0.148 \\
\hline ASCdMR & 3.16 & 0.28 & 2.93 & 0.18 & 0.004 \\
\hline LSChM & 4.25 & 0.43 & 4.06 & 0.45 & 0.191 \\
\hline LSCwM & 4.89 & 0.41 & 4.57 & 0.52 & 0.047 \\
\hline LSChwM & 0.87 & 0.08 & 0.89 & 0.07 & 0.408 \\
\hline LSCMR & 2.28 & 0.19 & 2.16 & 0.23 & 0.076 \\
\hline PSChM & 6.06 & 0.56 & 5.64 & 0.49 & 0.018 \\
\hline PSCwM & 5.92 & 0.45 & 5.65 & 0.42 & 0.063 \\
\hline PSChwM & 1.03 & 0.08 & 1.00 & 0.07 & 0.244 \\
\hline PSCMR & 3.00 & 0.23 & 2.82 & 0.21 & 0.020 \\
\hline $\mathrm{ChM}$ & 4.99 & 0.33 & 4.91 & 0.33 & 0.477 \\
\hline CwM & 3.72 & 0.24 & 3.79 & 0.25 & 0.377 \\
\hline ChwM & 1.35 & 0.06 & 1.30 & 0.06 & 0.019 \\
\hline CMR & 2.18 & 0.14 & 2.18 & 0.13 & 0.986 \\
\hline
\end{tabular}

\section{Applicability of Osipov et al. (2013) discriminant function to new populations}

When analyzing all three population samples together (German, Zulu, and Oneota), Osipov et al. (2013) function 1 predicted sex correctly for 68 of the 98 cases $(69.39 \%$ accuracy). When the German sample was analyzed alone, sex was correctly estimated for 20 of 30 cases $(66.67 \%$ accuracy). Similarly, applying function 1 to the Zulu sample resulted in correct prediction for 26 out of 38 cases $(68.42 \%$ accuracy). In the Oneota sample, function 1 estimated sex correctly for 22 of 30 cases (73.33\% accuracy). The computed kappa $(k)$ values for the above analyses indicate fair to moderate agreement between predicted and actual sex (Table 3).

\section{Cross-population discriminant functions for sexual dimorphism of the bony labyrinth}

The results of the step-wise cross-validated discriminant analyses are shown in Table 4. When analyzing all three

Table 8 Independent $t$ test results for sexual dimorphism in the Oneota sample. Mean values, standard deviation, and $P$ values. Mean values for height and width measurements are in $\mathrm{mm}, \mathrm{h} / \mathrm{w}, \mathrm{SLI}$ and $\mathrm{R}$ are indices. Significant $P$ values are in bold type. Abbreviations as in Table 2

Oneota sample

\begin{tabular}{lcccccc}
\hline & \multicolumn{2}{l}{ Males $(n=16)$} & & \multicolumn{2}{l}{ Females $(n=14)$} & \\
\cline { 2 - 3 } Variable & Mean & SD & & Mean & SD & $P$ value \\
\hline SLIM & 46.05 & 4.49 & & 47.28 & 4.29 & 0.452 \\
ASChM & 5.98 & 0.44 & & 5.58 & 0.53 & $\mathbf{0 . 0 3 0}$ \\
ASCwM & 7.03 & 0.46 & & 6.62 & 0.43 & $\mathbf{0 . 0 1 9}$ \\
ASChwM & 0.85 & 0.04 & & 0.84 & 0.04 & 0.484 \\
ASCMR & 3.25 & 0.21 & & 3.05 & 0.24 & $\mathbf{0 . 0 1 9}$ \\
ASCdhM & 6.50 & 0.50 & & 6.08 & 0.55 & $\mathbf{0 . 0 3 7}$ \\
ASCdwM & 6.60 & 0.38 & & 6.15 & 0.48 & $\mathbf{0 . 0 0 8}$ \\
ASCdhwM & 0.98 & 0.04 & & 0.99 & 0.05 & 0.770 \\
ASCdMR & 3.27 & 0.21 & & 3.06 & 0.24 & $\mathbf{0 . 0 1 5}$ \\
LSChM & 4.57 & 0.36 & & 4.22 & 0.57 & $\mathbf{0 . 0 4 7}$ \\
LSCwM & 5.04 & 0.24 & & 4.78 & 0.57 & 0.107 \\
LSChwM & 0.91 & 0.05 & & 0.88 & 0.06 & 0.213 \\
LSCMR & 2.40 & 0.14 & & 2.25 & 0.27 & 0.054 \\
PSChM & 6.11 & 0.61 & & 5.56 & 0.43 & $\mathbf{0 . 0 1 0}$ \\
PSCwM & 6.15 & 0.56 & & 5.66 & 0.40 & $\mathbf{0 . 0 1 1}$ \\
PSChwM & 0.99 & 0.04 & & 0.98 & 0.05 & 0.466 \\
PSCMR & 3.06 & 0.29 & & 2.81 & 0.20 & $\mathbf{0 . 0 0 9}$ \\
ChM & 5.02 & 0.18 & & 4.75 & 0.27 & $\mathbf{0 . 0 0 2}$ \\
CwM & 4.45 & 0.22 & & 4.16 & 0.17 & $\mathbf{0 . 0 0 0}$ \\
ChwM & 1.13 & 0.05 & & 1.14 & 0.05 & 0.549 \\
CMR & 2.37 & 0.09 & & 2.23 & 0.10 & $\mathbf{0 . 0 0 0}$ \\
\hline & & & & &
\end{tabular}


population samples together, the computed cross-validated success was $71.4 \%$. Discriminant analysis of the German population alone results in $70.0 \%$ accuracy. Cross-validated accuracy was $71.1 \%$ for the Zulu sample and $80.0 \%$ for the Oneota sample. Kappa statistics show significant agreement for all three populations together, as well as each individual population sample separately. According to the system proposed by Altman (1991), the kappa statistic computed for the German sample indicates fair agreement between the actual and predicted sex. The kappa statistics for the Zulu, Oneota, and mixedpopulations sample $(n=98)$ indicate moderate agreement between the actual and predicted sex (see Table 4). Based on the male and female centroids, the demarking point between males and females was established (the average of the two centroids) (Table 4). For example, the German sample demarking point is -0.120 with a male centroid of 0.388 and female centroid of -0.508 . Therefore, after the German sample function [(PSCMR $\times 4.262)+(-13.662)]$ is calculated, a resulting value $>$ -0.120 indicates a male and a value $<-0.120$ indicates a female. The closer the value is to either group centroid, the more likely the individual is of that sex (Table 4).

\section{Sexual dimorphism}

The independent $t$ tests demonstrated that some variables in all three population samples presented significant sexual dimorphism. When all samples (German, Zulu, and Oneota) are included $(n=98)$ in an independent $t$ test, significant sexual dimorphism is found in 14 variables: ASChM, ASCwM, ASCMR, ASCdhM, ASCdwM, ASCdMR, LSChM, LSCwM, LSCMR, PSChM, PSCwM, PSCMR, ChM, and CMR. These results along with the mean values for males and females are listed in Table 5. Mean values for males are larger across population samples.

The German sample has significant sexual dimorphism only in two particular posterior canal variables (see Table 6). The German mean values for males are larger than females for all variables except anterior canal diagonal height/ width and cochlea width (Table 6). The Zulu sample has significant sexual dimorphism for ten variables encompassing all three canals and the cochlea. Zulu males have larger mean values than females except for lateral height/width, cochlea width, and cochlea radius, (Table 7). The Norris Farms Oneota sample has significant sexual dimorphism for 13 variables (Table 8). Oneota males have larger mean values for most



Fig. 1 Principal component analysis, PC 1 and PC 2 ( 66\% of variance). German females: pink squares; German males: red crosses; Zulu females: blue triangles; Zulu males: blue squares; Oneota females: green diamonds; Oneota males: green x's 
variables. The mean values for anterior diagonal height/ width and cochlear height/width were larger in Oneota females (Table 8).

\section{Bilateral asymmetry}

Significant bilateral asymmetry was found in several variables for all population groups. When all samples are analyzed together $(n=98)$, left and right bony labyrinths differed for seven variables on the posterior canal and cochlea (Online resource 4). The sagittal labyrinthine index also showed significant bilateral asymmetry. The variables displaying asymmetry differed within the German, Zulu, and Oneota samples. The German sample was asymmetric for eight variables on the anterior and posterior canals and the cochlea, (Online resource 5). The Zulu had seven asymmetrical variables on the anterior and posterior canals and cochlea that showed significant left/right differences (Online resource 6). The sagittal labyrinthine index was also included in these seven asymmetrical variables. The Oneota sample displayed no significant asymmetry (Online resource 7).

\section{Principal components analysis}

In the PCA, the first three components account for $72.49 \%$ of the total variance. Overall, all three samples (German, Zulu, and Oneota) overlap. The majority of the Zulu and Oneota females are on the negative side of PC 1 (49.81\% of variance, 10.46 eigenvalue) (Fig. 1). For each population, the male convex hull is located more in the positive direction while the female convex hulls are more in the negative direction. Loadings indicate that PC 1 is mostly driven by size, with all variables loading positively. PC 2 (15.57\% of variance, 3.27 eigenvalue) is driven by cochlear width and cochlea radius (loading negatively) as well as cochlear $\mathrm{h} / \mathrm{w}$, posterior canal $\mathrm{h} / \mathrm{w}$, anterior canal $\mathrm{h} / \mathrm{w}$, anterior diagonal $\mathrm{h} / \mathrm{w}$, and SLI (loading positively) (Online resource 8). PC 2 separates the Oneota sample on its negative axis and the German and Zulu samples tend to push towards the positive side of PC 2. PC 3 ( $7.11 \%$ of variance, 1.49 eigenvalue) shows the same overlapping of sexes from any one population as well as sample overlap (Fig. 2). The largest convex hulls are the male German sample, the male Zulu sample, and female Zulu sample. The Zulu males and females as well as the Oneota males and females do not overlap as much with each other as the male and female Germans do. The German female convex hull sits almost completely within the German male convex hull (Fig. 2).

\section{Inter-population variation}

The results of the one-way ANOVAs revealed significant differences among the three populations for all variables, (see

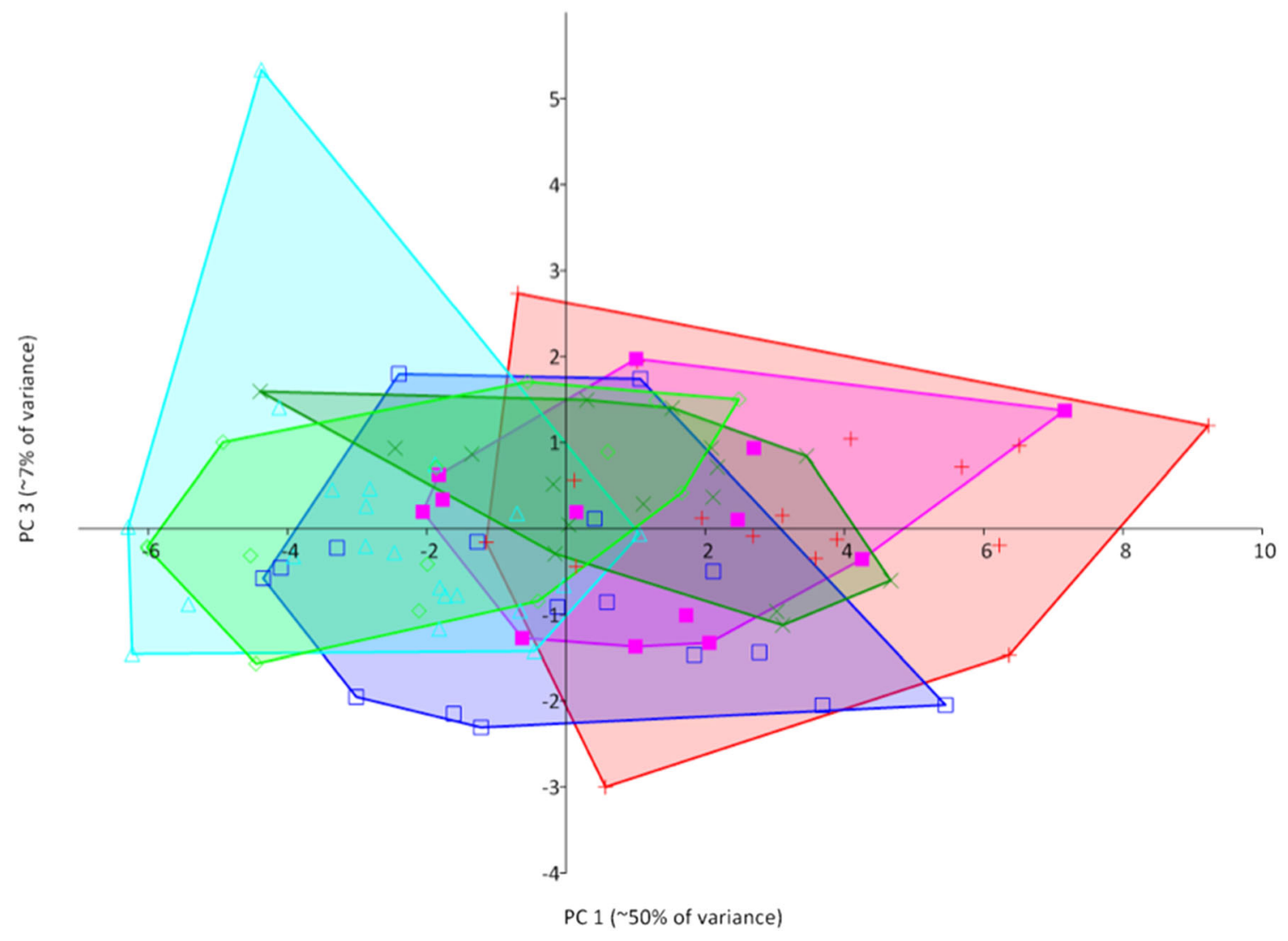

Fig. 2 Principal component analysis, PC 1 and PC 3 ( $\sim 57 \%$ of variance). Legend as in Fig. 1 
Table 9 ANOVA results for population differences. Mean values, standard deviation, $\mathrm{F}$ - and $P$ values for mean differences between the three populations (German, Zulu, Oneota). Height and width means in $\mathrm{mm}, \mathrm{h} / \mathrm{w}$, SLI, and R are indices. Significant values are in bold type.

Abbreviations as in Table 2

\begin{tabular}{|c|c|c|c|c|c|c|c|c|c|c|}
\hline \multirow[b]{2}{*}{ Variable } & \multicolumn{2}{|c|}{$\begin{array}{l}\text { All samples } \\
(n=96)\end{array}$} & \multicolumn{2}{|c|}{$\begin{array}{l}\text { German } \\
(n=30)\end{array}$} & \multicolumn{2}{|c|}{ Zulu $(n=38)$} & \multicolumn{2}{|c|}{$\begin{array}{l}\text { Oneota } \\
(n=30)\end{array}$} & \multicolumn{2}{|c|}{ ANOVA results } \\
\hline & Mean & SD & Mean & SD & Mean & $\mathrm{SD}$ & Mean & SD & $F$ value & $P$ value \\
\hline SLIM & 48.95 & 5.41 & 48.66 & 4.74 & 51.03 & 5.94 & 46.62 & 4.37 & 6.446 & 0.003 \\
\hline ASChM & 5.89 & 0.57 & 6.23 & 0.54 & 5.68 & 0.51 & 5.80 & 0.52 & 10.475 & 0.000 \\
\hline ASCwM & 6.72 & 0.54 & 6.91 & 0.52 & 6.47 & 0.51 & 6.84 & 0.49 & 7.612 & 0.001 \\
\hline ASChwM & 0.88 & 0.05 & 0.90 & 0.05 & 0.88 & 0.04 & 0.85 & 0.04 & 14.824 & 0.000 \\
\hline ASCMR & 3.15 & 0.27 & 3.29 & 0.25 & 3.04 & 0.25 & 3.16 & 0.24 & 8.639 & 0.000 \\
\hline ASCdhM & 6.42 & 0.61 & 6.85 & 0.55 & 6.17 & 0.54 & 6.31 & 0.55 & 14.168 & 0.000 \\
\hline ASCdwM & 6.26 & 0.55 & 6.50 & 0.52 & 5.97 & 0.51 & 6.39 & 0.48 & 10.444 & 0.000 \\
\hline ASCdhwM & 1.03 & 0.05 & 1.06 & 0.05 & 1.03 & 0.04 & 0.99 & 0.04 & 18.051 & 0.000 \\
\hline ASCdMR & 3.17 & 0.28 & 3.34 & 0.25 & 3.04 & 0.26 & 3.17 & 0.25 & 11.882 & 0.000 \\
\hline LSChM & 4.41 & 0.55 & 4.74 & 0.55 & 4.14 & 0.45 & 4.41 & 0.49 & 12.516 & 0.000 \\
\hline LSCwM & 4.87 & 0.49 & 5.04 & 0.47 & 4.71 & 0.50 & 4.91 & 0.44 & 4.063 & 0.019 \\
\hline LSChwM & 0.90 & 0.07 & 0.94 & 0.06 & 0.88 & 0.07 & 0.90 & 0.05 & 7.867 & 0.001 \\
\hline LSCMR & 2.32 & 0.25 & 2.44 & 0.25 & 2.21 & 0.22 & 2.33 & 0.22 & 8.697 & 0.000 \\
\hline PSChM & 6.12 & 0.71 & 6.72 & 0.63 & 5.83 & 0.56 & 5.85 & 0.60 & 23.619 & 0.000 \\
\hline PSCwM & 5.92 & 0.49 & 6.11 & 0.44 & 5.77 & 0.45 & 5.92 & 0.54 & 4.154 & 0.019 \\
\hline PSChwM & 1.03 & 0.08 & 1.10 & 0.07 & 1.01 & 0.07 & 0.99 & 0.05 & 29.658 & 0.000 \\
\hline PSCMR & 3.01 & 0.28 & 3.21 & 0.25 & 2.90 & 0.23 & 2.94 & 0.28 & 13.907 & 0.000 \\
\hline $\mathrm{ChM}$ & 5.04 & 0.34 & 5.30 & 0.30 & 4.95 & 0.33 & 4.90 & 0.26 & 16.634 & 0.000 \\
\hline CwM & 3.95 & 0.35 & 3.82 & 0.29 & 3.76 & 0.25 & 4.31 & 0.24 & 50.777 & 0.000 \\
\hline ChwM & 1.29 & 0.12 & 1.39 & 0.09 & 1.32 & 0.06 & 1.14 & 0.05 & 163.596 & 0.000 \\
\hline CMR & 2.24 & 0.14 & 2.28 & 0.13 & 2.18 & 0.13 & 2.30 & 0.12 & 9.286 & 0.000 \\
\hline
\end{tabular}

Table 9). Subsequently, the Tukey post-hoc tests identified which pairs of populations significantly differed (i.e., German, Zulu, and Oneota) for each variable (Online resource 9). Particularly, the Zulu sample has the largest SLI with a mean of 51.03, followed by the German (48.92) and the Oneota samples (46.62). For the raw height and width variables, the Oneota sample has values smaller than the German sample but larger than the Zulu sample, with the exception of ChM. The height/width indices for the Zulu are smaller than the Germans but larger than the Oneota in all cases, except for the lateral canal (LSChwM). The largest canal and cochlear radii were observed in the German population sample, followed by the Oneota and the Zulu. Overall, in most variables, German individuals presented the greatest size.

\section{Geometric mean adjusted data}

The same discriminant success rates were achieved either using the original or the size-adjusted variables (see Table 4). This was the case both for the cross-population function as well as for the equations developed for each population separately. The same variables (PSCMR for crosspopulations and the German sample, ASCMR for the Zulu sample, and CMR for the Oneota) were the most discriminant in the size-adjusted discriminant analysis as in the non-size adjusted one (see Table 4).

The PCA analysis based on the size-adjusted variables captured less variation in its first three PCs than the non-corrected PCA. The first three PCs account for $60.41 \%$ of the variation. PC 1 (30.01\% of variation), PC 2 (16.70\% of variation), and PC 3 (13.84\% of variation) do not clearly separate males from females for any of the three samples. However, PC 1 tends to separate the Germans (higher values on the component) from the Oneota and Zulu samples, which presented negative values on PC 1. Furthermore, PC 2 seems to separate the Oneota from the Zulu samples. Based on the factor loadings, cochlear height and width are pushing the Oneota and Zulu away from the German sample (see online resources 1 and 2 and PC loadings in online resource 10).

\section{Discussion}

Osipov et al. (2013) found sexual dimorphism of the bony labyrinth in a Cretan population and developed functions to be used for sex estimation, which had $82.4 \%$ classification accuracy. When their function 1 was applied to the three population samples examined here, the classification accuracy was overall lower than that reported in the 2013 paper: 
$66.67 \%$ for the German, $68.42 \%$ for the Zulu, and $73.33 \%$ for the Oneota samples. Osipov et al. (2013) warned that the discriminant functions are likely population specific, a hypothesis supported by our results. As the results of the $t$ tests, discriminant analyses and PCAs indicate, our German sample has the lowest levels of sexual dimorphism of the three samples studied. The Osipov et al. (2013) function worked with higher accuracy on the samples presenting greater sexual dimorphism: our North American and South African specimens.

In an attempt to create more accurate sex estimation functions, a cross-validated step-wise discriminant analysis was carried out on the German, Zulu, and Oneota data. All population-specific functions had higher cross-validated discriminant accuracy (Table 4) than the application of the Osipov et al. function (2013) to the samples (Table 3). Additionally, our population-specific and mixed-sample functions (based on a single variable) achieve higher classification success rates than the Osipov et al. (2013) function, which requires three variables. For our mixed-samples dataset $(n=$ 98) and our German sample, the cross-validated step-wise discriminant analysis reveals that posterior canal radius is highly sexually dimorphic, as previously reported by Osipov et al. (2013). However, for the Oneota sample, the cochlear radius was the most powerful predictor of sex, even though it was not used in any of the six discriminant functions created by Osipov et al. (2013). The Zulu sample had anterior canal radius as the most sexually dimorphic variable. We also used our combined population sample to develop a discriminant function for estimating sex across populations. Our new cross-population function (Table 4), however, performed only slightly better $(\sim 2 \%)$ than Function 1 from Osipov et al. (2013): the cross-population function achieved $71.4 \%$ classification success.

The independent $t$ test showed that sexual dimorphism in the bony labyrinth characterizes all three populations. However, different bony labyrinth dimensions are sexually dimorphic within each population. Within the German sample, significant sexual dimorphism was only found for posterior canal height, and posterior canal radius (Table 6). This means that German males have taller posterior canals than females and larger posterior canal radii (PSCMR). Osipov et al. (2013) also reported that the posterior canal had the most sexual dimorphism in the Cretan sample. The larger posterior canal and radius may be a result of sexual dimorphism in the surrounding petrous portion. In comparison, the Zulu had many more sexually dimorphic variables (see Table 7). Size variables for the anterior canal (and anterior diagonal) as well as the lateral and posterior canal were significantly different between Zulu males and females with males having larger mean values. The anterior canal (and anterior diagonal) radii as well as the posterior canal radius showed significant sexual dimorphism. For these radii variables, Zulu males have overall larger anterior and posterior semi-circular canals than Zulu females do. The shape variable for cochlear height compared to cochlear width (ChwM) was significantly different between Zulu males and females. For cochlear shape, while both males and females have a mean Chw above 1 (meaning height is larger than width), the males have a higher mean (1.35) than females (1.30), meaning Zulu males have an even higher cochlea (relative to width) than Zulu females. These sexually dimorphic differences in the Zulu may reflect higher levels of sexual dimorphism in the crania among this sample than in the German sample. The Oneota sample had high levels of sexual dimorphism for size variables (Table 8). There was significant sexual dimorphism of height and width in the anterior, lateral, and posterior canals as well as the cochlea. As indicated by significant sexual dimorphism in the radii variables, Oneota males have overall larger anterior and posterior semi-circular canals and a larger cochlea than Oneota females.

Since at least some parts of the bony labyrinth develop reflecting their surrounding petrous portion anatomy (Jeffery and Spoor 2004), sexual dimorphism of the bony labyrinth is most likely the result of sexual dimorphism of the surrounding petrous portion bone. The petrous portion has also been found to be sexually dimorphic (i.e., Kalmey and Rathbun 1996; Wahl and Graw 2001) and thus, it is unlikely that sexual dimorphism of the bony labyrinth is the result of differential selection for inner ear functions in males and females. The differing levels of sexual dimorphism present in the samples studied here may be a reflection of differing levels of sexual dimorphism in the overall cranial morphology of these populations. Previous work suggests numerous underlying causes for differential sexual dimorphism in modern human populations such as nutritional stress and division of labor (i.e., Stini 1969; Stini 1972; Holden and Mace 1999), or subsistence practices and temperature (i.e., Wolfe and Gray 1982; Frayer and Wolpoff 1985).

As reported by Osipov et al. (2013), we also found bilateral asymmetry in the bony labyrinth. The asymmetry found here was population specific, with differing variables being significantly asymmetric depending on the population. Although the Oneota sample did not exhibit significant asymmetry, this is most likely due to the fact that only 18 individuals could be included in this analysis, because 12 specimens only had one side available for study.

The PCA analysis confirms that the size of the bony labyrinth presents significant sexual dimorphism. The German sample displays less sexual dimorphism than both the Zulu and Oneota samples. This may be linked to various levels of sexual dimorphism of the surrounding petrous portion, temporal bone, or even the crania, as discussed above.

By contrast, the size-adjusted PCA shows that differences among the population samples are mainly driven by shape as opposed to size (Online resources 1 and 2). In the sizeadjusted PCA, the males and females mostly overlap and are 
not as clearly separated as in the original PCA (Figs. 1 and 2) indicating that size is the major factor (although not the sole factor, as indicated by the second discriminant analysis and the $t$ tests) of male and female differences.

Previous research on the bony labyrinth in various strepsirrhine taxa by Lebrun et al. (2010) reported that, although bony labyrinth morphology is functionally constrained, it does conserve strong neutral evolution signals consistent with a random walk model. As was found by Lebrun et al. (2010) in the strepsirrhine taxa, perhaps human population differences in the bony labyrinth are also the result of neutral evolution. Population differences in bony labyrinth morphology could be the result of differing temporal bone morphology. The temporal bone has been shown to preserve population history well (Harvati and Weaver 2006; ReyesCenteno et al. 2014, 2017), and perhaps the bony labyrinth, which takes its form at least partially from the surrounding petrous portion (Jeffery and Spoor 2004), exhibits population differences since its surrounding bony tissues are also population specific. Thus, the petrous portion seems to be not only sexually dimorphic but also a good preserver of population history. Smith et al. (2007) reported that temporal bone shape (but not size) reflected neutral evolution as opposed to an association with climate, temperature, or altitude, while Smith et al. (2013) found that temporal bone morphology followed an isolation-by-distance model of evolution, reflecting population history from early on in ontogeny (by 5 years of age). This hypothesis was recently confirmed by Ponce de León et al. (2018), who reported that the human bony labyrinth morphology itself tracks genetic distances in an isolation-by-distance model. Based on the wide array of research on the bony labyrinth discussed above, bony labyrinth morphology is affected by multiple forces such as population history, surrounding (sexually dimorphic) cranial structures, and neutral evolution.

\section{Conclusions}

Our findings show that the level of sexual dimorphism in the bony labyrinth seems to vary across population groups. As a consequence, the function previously developed by Osipov et al. (2013) was less accurate for our population samples. For this purpose, we developed new functions for sex determination based on three distinct population samples, whose classification accuracy rates ranged from 70 to $80 \%$. The newly developed functions require fewer variables than the Osipov et al. (2013) function, increasing their applicability on incomplete bony labyrinths. The single most dimorphic variables were the canal and cochlear radii. Both sexual dimorphism and bilateral asymmetry of the bony labyrinth were found to be population specific. Sexual dimorphism was more evident in the size of individuals, while population differences were driven mostly by shape differences. Overall, the morphology of the bony labyrinth seems to be affected by a complex interaction among different factors, including sex and population history. This pattern seems to reflect the ones previously observed for the surrounding sexually dimorphic petrous portion as well as the population-specific temporal bone.

Acknowledgments We thank K. Carlson and T. Jashashvili for their work scanning the Zulu sample and B. Billings for access to the Dart collection. We also thank T.J. Martin and the Illinois State Museum for access to the Norris Farms Oneota, G. Milner for access and collection information, T. Ryan and T. Stecko for their scanning work, and C. Hill for access to temporal scans for several individuals. We also thank M. Francken, W. Binczik, C. Bauer, and L. Kellner for their help with the German sample and to Hugo Reyes-Centeno for statistical and technical advice. Alexandra Uhl was supported by a research grant from the L.S.B. Leakey Foundation.

Funding information Open Access funding provided by Projekt DEAL. This research was made possible through a Deutsche Forschungsgemeinschaft (DFG) major instrumentation grant (DFG INST 37/706-1 FUGG) and the L.S.B. Leakey Research Grant.

Open Access This article is licensed under a Creative Commons Attribution 4.0 International License, which permits use, sharing, adaptation, distribution and reproduction in any medium or format, as long as you give appropriate credit to the original author(s) and the source, provide a link to the Creative Commons licence, and indicate if changes were made. The images or other third party material in this article are included in the article's Creative Commons licence, unless indicated otherwise in a credit line to the material. If material is not included in the article's Creative Commons licence and your intended use is not permitted by statutory regulation or exceeds the permitted use, you will need to obtain permission directly from the copyright holder. To view a copy of this licence, visit http://creativecommons.org/licenses/by/4.0/.

\section{References}

Altman DG (1991) Practical statistics for medical research. Chapman and Hall, London, England

Bouchneb L, Crevecoeur I (2009) The inner ear of Nazlet Khater 2 (Upper Paleolithic, Egypt). J Hum Evol 56:257-262

Braga J, Thackeray JF, Dumoncel J, Descouens D, Bruxelles L, Loubes JM, Kahn J-L et al (2013) A new partial temporal bone of a juvenile hominin from the site of Kromdraai B (South Africa). J Hum Evol 65:447-456

Cohen J (1960) A coefficient of agreement for nominal scales. Educ Psychol Meas 20:37-46

Cox PG, Jeffery N (2010) Semicircular canals and agility: the influence of size and shape measures. J Anat 216:37-47

El Khoury M, Braga J, Dumoncel J, Nancy J, Esclassan R, Vaysse F (2014) The human semicircular canals orientation is more similar to the bonobos than to the chimpanzees. PLoS One 9:e93824

Falsetti AB, Jungers WL, Colle TM (1993) Morphometrics of the callitrichid forelimb: a case study in size and shape. Int J Primatol 1:551-572

Field A (2013) Discovering statistics using SPSS. SAGE, London

Frayer DW, Wolpoff MH (1985) Sexual dimorphism. Annu Rev Anthropol 14:429-473 
Graw M, Wahl J (1999) Metric sex differentiation of the pars petrosa ossis temporalis. Int J Legal Med 114:215-223

Graw M, Wahl J (2000) Die Wertigkeit morphognostischer Geschlechtsmerkmale am rezenten Schädel. In: Rothschild MA (ed) Das neue Jahrtausend: Herausforderungen an die Rechtsmedizin. Festschrift Volkmar Schneider, Schmidt-Römhild. Schmidt-Römhild, Lübeck, pp 387-405

Graw M, Wahl J, Albrecht M (2005) Course of the meatus acusticus internus as criterion for sex differentiation. Forensic Sci Int 147: $113-117$

Gunz P, Ramsier M, Kuhrig M, Hublin J-J, Spoor F (2012) The mammalian bony labyrinth reconsidered, introducing a comprehensive geometric morphometric approach. J Anat 220:529-543

Hammer Ø, Harpet D, Ryan P (2001) Paleontological statistics package for education and data analysis. Palaeontol Electron 4:9

Hardy M (1938) The length of the organ of Corti in man. Am J Anat 62: 291-311

Harvati K, Weaver TD (2006) Human cranial anatomy and the differential preservation of population history and climate signatures. Anat Rec A: Discov Mol Cell Evol Biol 288:1225-1233

Hill CA, Radovčić J, Frayer DW (2014) Brief communication: investigation of the semicircular canal variation in the Krapina Neandertals. Am J Phys Anthropol 154:302-306

Holden C, Mace R (1999) Sexual dimorphism in stature and women's work: a phylogenetic cross-cultural analysis. Am J Phys Anthropol 110:27-45

Hublin J-J, Spoor F, Braun M, Zonneveld F, Condemi S (1996) d) A late Neanderthal associated with Upper Palaeolithic artefacts. Nature 381:224-226

Jeffery N, Spoor F (2004) Prenatal growth and development of the modern human labyrinth. J Anat 204:71-92

Kalmey JK, Rathbun TA (1996) Sex determination by discriminant function analysis of the petrous portion of the temporal bone. J Forensic Sci 41:865-867

Lague MR, Collard NJ, Richmond BG, Wood BA (2008) Hominid mandibular corpus shape variation and its utility for recognizing species diversity within fossil Homo. J Anat 213:670-685

Lebrun R, De León MP, Tafforeau P, Zollikofer C (2010) Deep evolutionary roots of strepsirrhine primate labyrinthine morphology. J Anat 216:368-380

Miller JD (2007) Sex differences in the length of the organ of Corti in humans. J Acoust Soc Am 121:151-155

Milner GR, Smith VG (1990) Oneota human skeletal remains. In: Santure SK, Harn AD, Esarey D (eds) Archaeological investigations at the Morton Village and Norris Farms 36 Cemetery, 45th edn. Illinois state museum reports of investigations, Springfield, pp 111-148

Osipov B, Harvati K, Nathena D, Spanakis K, Karantanas A, Kranioti EF (2013) Sexual dimorphism of the bony labyrinth: a new ageindependent method. Am J Phys Anthropol 151:290-301

Ponce de León MS, Koesbardiati T, Weissmann JD, Milella M, ReynaBlanco CS, Suwa G, Kondo O, Malaspinas A-S, White TD, Zollikofer CPE (2018) Human bony labyrinth is an indicator of population history and dispersal from Africa. Proc Natl Acad Sci. https://doi.org/10.1073/pnas.1717873115

Reyes-Centeno H, Ghirotto S, Détroit F, Grimaud-Hervé D, Barbujani G, Harvati K (2014) Genomic and crani-al phenotype data support multiple modern human dispersals from Africa and a southern route into Asia. Proc Natl Acad Sci 111:7248-7253

Reyes-Centeno H, Ghirotto S, Harvati K (2017) Genomic validation of the differential preservation of population history in modern human cranial anatomy. Am J Phys Anthropol 162:170-179

Sato H, Sando I, Takahasi H (1991) Sexual dimorphism and development of the human cochlea. Acta Otolaryngol 111:10371040

Smith HF, Terhune CE, Lockwood CA (2007) Genetic, geographic, and environmental correlates of human temporal bone variation. Am J Phys Anthropol 134:312-322

Smith HF, Ritzman T, Otárola-Castillo E, Terhune CE (2013) A 3-D geometric morphometric study of intraspecific variation in the ontogeny of the temporal bone in modern Homo sapiens. J Hum Evol 65:479-489

Spoor F (1993) The comparative morphology and phylogeny of the human bony labyrinth. University of Utrecht, Utrecht

Spoor F (2003) The semicircular canal system and locomotor behaviour, with special reference to hominin evolution. CourierForschungsinstitut Senckenberg 243:93-104

Spoor F, Zonneveld F (1995) Morphometry of the primate bony labyrinth: a new method based on high-resolution computed tomography. J Anat 186:271-286

Spoor F, Zonneveld F (1998) Comparative review of the human bony labyrinth. Am J Phys Anthropol 107:211-251

Spoor F, Wood B, Zonneveld F (1994) Implications of early hominid labyrinthine morphology for evolution of human bipedal locomotion. Nature 369:645-648

Stini WA (1969) Nutritional stress and growth: sex difference in adaptive response. Am J Phys Anthropol 31:417-426

Stini WA (1972) Reduced sexual dimorphism in upper arm muscle circumference associated with protein-deficient diet in a South American population. Am J Phys Anthropol 36:341-351

Stone AC, Stoneking M (1998) mtDNA analysis of a prehistoric Oneota population: implications for the peopling of the New World. Am J Hum Genet 62:1153-1170

Stone AC, Milner GR, Paabo S, Stoneking M (1996) Sex determination of ancient human skeletons using DNA. Am J Phys Anthropol 99: 231-238

Tabachnick B, Fidell LS (2001) Using multivariate statistics. Harper Collins, New York

Uhl A, Reyes-Centeno H, Grigorescu D, Kranioti EF, Harvati K (2016) Inner ear morphology of the Cioclovina early modern European calvaria from Romania. Am J Phys Anthropol 160:62-70

Wahl J, Graw M (2001) Metric sex differentiation of the pars petrosa ossis temporalis. Int J Legal Med 114:215-223

Wahl J, Henke W (1980) Die Pars petrosa als Diagnostikum für die multivariat-biometrische Geschlechtsbestimmung von Leichenbrandmaterial. Z Morphol Anthropol 70:258-268

Wolfe LD, Gray JP (1982) A cross-cultural investigation into the sexual dimorphism of stature. In: Hall RL (ed) Sexual dimorphism in Homo sapiens. Praeger, New York, pp 197-230

Publisher's note Springer Nature remains neutral with regard to jurisdictional claims in published maps and institutional affiliations. 